\title{
EVALUASI PERTUMBUHAN AWAL KEBUN BENIH SEMAI UJI KETURUNAN SENGON (Falcataria moluccana sinonim : Paraserianthes falcataria) UMUR 4 BULAN DI CIKAMPEK JAWA BARAT
}

\author{
Early Growth Evaluation of Sengon (Falcataria moluccana synonim : Paraserianthes \\ falcataria) Seedling Seed Orchard at 4 Months of Age in Cikampek West Java
}

Yayan Hadiyan

Balai Besar Penelitian Bioteknologi dan Pemuliaan Tanaman Hutan Jl. Palagan Tentara Pelajar Km 15, Purwobinangun, Pakem, Yogyakarta Telp. 0274-895954, Fax 0274-896080

Naskah masuk : 8 Juni 2009 ; Naskah diterima : 3 Februari 2010

\begin{abstract}
Increasing demand for seed of sengon (Falcataria moluccana) has occured due to expansion of sengon plantation forest that grew widely in Indonesia. On the other hand, good quality of the seed supply was very limited to enhance its productivity. One of the research activities in creating genetically improved seed has been undertaken by Centre for Forest Biotechnology and Tree Improvement Research and Development Yogyakarta through establishing sengon seedling seed orchard (SSO) located in Cikampek, West Java. The research objective was to evaluate the growth and genetic parameters of the sengon seedling seed orchard at four months old. The SSO was arranged into a randomize completely block design, 80 families, 4 treeplots and 6 blocks. Research variables observed consisted of survival, tree height, stem diameter and some genetics paramaters. The result showed that survival average ranged from $82.47 \%$ to 93.38), while variance analysis on stem diameter and tree height were significantly differences. The average of diameter growth was $0.87 \mathrm{~cm}$ and height was $0.76 \mathrm{~m}$. Heritability of diameter $\left(h^{2}=0.10\right)$ and height $\left(h^{2}=0.16\right)$ were classified as moderate. Genetic correlation between diameter and height was strong $\left(r_{g}=0.90\right)$ and higher then the phenotipe $\left(r_{p}=0.78\right)$.
\end{abstract}

Key words : seedling seed orchard, Falcataria moluccana, growth, heritability, genetic correlation

\begin{abstract}
ABSTRAK
Kebutuhan benih sengon (Falcataria moluccana) terus meningkat, seiring dengan bertambah luasnya hutan tanaman sengon di Indonesia. Sementara itu, keberadaan benih sengon berkualitas untuk meningkatkan produktivitasnya masih terbatas. Salah satu kegiatan penelitian dalam rangka menghasilkan benih sengon bergenetik baik, telah dilakukan oleh Balai Besar Penelitian Bioteknologi dan Pemuliaan Tanaman Hutan Yogyakarta melalui pembangunan Kebun Benih Semai Uji Keturunan Sengon di Cikampek Jawa Barat. Tujuan penelitian ini adalah untuk mengevaluasi kinerja pertumbuhan dan parameter genetik kebun benih sengon tersebut pada umur 4 bulan. Kebun benih ini didisain menggunakan Rancangan Acak Lengkap Berblok (RALB) yang terdiri dari 80 famili, 4 treeplot dan 6 blok. Variabel penelitian yang diamati adalah persen hidup, pertumbuhan dan beberapa paramater genetik. Hasil analisa menunjukkan bahwa persen hidup rata-rata sengon berkisar antara 82,47\% sampai dengan $93,38 \%$, sedangkan hasil analisis varian terhadap diameter batang dan tinggi tanaman menunjukkan berbeda nyata. Pertumbuhan rerata diameter batang mencapai $0,87 \mathrm{~cm}$ dan tinggi $0,76 \mathrm{~m}$. Taksiran nilai heritabilitas diameter $\left(\mathrm{h}_{\mathrm{i}}^{2}=0,10\right)$ dan tinggi $\left(\left(h_{i}^{2}=0,16\right)\right)$ termasuk klasifikasi sedang/moderat. Korelasi genetik diameter $x$ tinggi cukup kuat $\left(\mathrm{r}_{\mathrm{g}}=0,90\right)$ dan lebih tinggi dari korelasi fenotip $\left(\mathrm{r}_{\mathrm{p}}=0,78\right)$.
\end{abstract}

Kata kunci: kebun benih sengon, Falcataria moluccana, pertumbuhan, heritabilitas, korelasi genetik 


\section{PENDAHULUAN}

Permintaan benih sengon berkualitas semakin hari semakin meningkat seiring dengan berkembang luasnya hutan tanaman sengon baik yang ditanam oleh masyarakat maupun perusahaan swasta. Sengon (Falcataria moluccana sinonim : Paraserianthes falcataria) merupakan tanaman asli yang tersebar di Maluku, Papua, Papua New Guinea, Pulau Solomon dan Taompala (Sulawesi Selatan). Menurut Achmad dkk. (2004) tanaman ini dibawa oleh Teysmann untuk ditanam di Kebun Raya Bogor pada tahun 1871. Tanaman sengon mulai banyak dikembangkan sebagai hutan rakyat karena dapat tumbuh pada sebaran kondisi iklim yang luas, tidak menuntut persyaratan tempat tumbuh yang tinggi dan mempunyai banyak manfaat seperti bahan bangunan ringan di bawah atap, bahan baku pulp dan kertas, peti kemas, papan partikel dan daunnya sebagai pakan ternak (Syahri, 1991).

Menurut Siregar dkk. (2008), prospek penanaman sengon cukup baik. Hal ini disebabkan oleh karena kebutuhan akan kayu sengon mencapai $500.000 \mathrm{~m}^{3}$ per tahun. Pada tahun 2003, harga kayu sengon di pasaran mencapai Rp. $250.000 / \mathrm{m}^{3}$, tetapi kini harga kayu sengon meningkat pesat menjadi Rp. 650.000/ $\mathrm{m}^{3}$. Riap pertumbuhan sengon baru mencapai 20 $\mathrm{m}^{3} /$ ha/tahun (Alrasyid, 1997), sedangkan di kecamatan Sapuran, Wonosobo hutan rakyat sengon dengan berbagai pola usahatani mencapai riap volume tahunan sebesar $16,8 \mathrm{~m}^{3} /$ ha/tahun (pada umur 8 tahun) dengan rata-rata produksi $134,2 \mathrm{~m}^{3} /$ ha (Andayani, 2003).

Dalam upaya meningkatkan riap volume sengon, Balai Besar Penelitian Bioteknologi dan Pemuliaan Tanaman Hutan pada tahun 2008 telah membangun Kebun Benih Semai Uji Keturunan (KBSUK) Sengon yang berlokasi di Hutan Penelitian Pusat Penelitian dan Pengembagan Hutan Tanaman di Cikampek. Plot ini merupakan plot ulangan dari KBSUK sengon yang telah dibangun di Kediri yang pengamatannya dihentikan sementara oleh karena serangan karat tumor (rust gall). Plot KBSUK yang di Kediri kemudian dikonversi menjadi plot uji karakter adaptif, misalnya untuk resistensi sengon di masa datang.

Tujuan penelitian ini adalah untuk mengevaluasi sifat pertumbuhan dan parameter genetik tanaman KBSUK Sengon pada umur 4 bulan.

\section{BAHAN DAN METODE}

\section{A. Tempat dan Waktu Penelitian}

Penelitian dilakukan pada bulan Maret 2009 di KHDTK Cikampek yang merupakan wilayah kerja Pusat Penelitian dan Pengembangan Hutan Tanaman Bogor.

Tabel(Table) 1. Sumber benih dan jumlah famili yang diuji pada KBSUK Sengon di Cikampek (Seed source and the number of families tested in Seedling Seed Orchard of Sengon in Cikampek)

\begin{tabular}{|c|l|c|l|c|}
\hline No. & $\begin{array}{c}\text { Asal pohon induk } \\
\text { (Mother tree origin) }\end{array}$ & $\begin{array}{c}\text { Jumlah famili } \\
\text { (Number of family) }\end{array}$ & $\begin{array}{c}\text { Posisi Koordinat } \\
\text { (Coordinate position) }\end{array}$ & $\begin{array}{c}\text { Ketinggian tempat } \\
\text { (Altitude) (m dpl) }\end{array}$ \\
\hline 1. & Candiroto* & 24 & $7^{0} 15^{\prime} \mathrm{LS}-110^{0} 09^{\prime} \mathrm{BT}$ & 500 \\
\hline 2. & Biak Papua & 19 & $1^{0} 1^{\prime} \mathrm{LS}-123^{0} 47^{\prime} \mathrm{BT}$ & 70 \\
\hline 3. & Wamena & 11 & $4^{0} 1^{\prime} \mathrm{LS}-139^{0} 10^{\prime} \mathrm{BT}$ & 1700 \\
\hline 4. & Lombok & 17 & $\begin{array}{l}08^{0} 18-08^{0} 32 \mathrm{LS} \text { dan } \\
116^{0} 07^{\prime}-116^{0} 23^{\prime}\end{array}$ & $101-665$ \\
\hline 5. & Kediri & 9 & $\begin{array}{l}07^{0} 48^{\prime}-07^{0} 56^{\prime} \mathrm{LS} \text { dan } \\
112^{0} 11^{\prime}-112^{0} 15^{\prime} \mathrm{BT}\end{array}$ & $121-618$ \\
\hline
\end{tabular}

Keterangan(Remarks): Sumber benih Candiroto, Kediri dam Lombok termasuk ras lahan dimana pohon induk sengon (famili) itu telah tumbuh dan beradaptasi untuk menghasilkan satu generasi (benih) di Candiroto Temanggung, tetapi sebaran asli famili-famili bukanlah asli setempat.

\section{B. Bahan Penelitian}

Bahan penelitian yang digunakan adalah tanaman sengon pada kebun benih semai uji keturunan sengon yang berada di Hutan
Penelitian Kawasan Hutan dengan Tujuan Khusus (KHDTK) Cikampek Kabupaten Karawang Jawa Barat, yang merupakan areal kerja Pusat Penelitian dan Pengembangan Hutan Tanaman (P3HT) Bogor. 
Kebun benih ini dirancang mengikuti Randomized Completely Block Design (RCBD) yang terdiri dari 6 blok, 80 famili dan 4 treeplot. Sebagian besar famili-famili yang diuji berasal dari Kebun Benih Semai Uji Keturunan Sengon generasi I dan ditambah famili-famili baru dari daerah lain sebagai materi infusi yang secara lengkap disajikan pada Tabel 1.

\section{Metode Penelitian}

Penelitian ini diawali dengan melakukan pengukuran sifat pertumbuhan tanaman sengon di plot kebun benih uji keturunan semai sengon ini. Karena tanaman uji masih berumur 4 bulan, maka sifat pertumbuhan yang diukur meliputi 2 sifat saja yaitu diameter $(10 \mathrm{~cm}$ dari pangkal batang) dan tinggi tanaman. Data ini kemudian dianalisis untuk mengetahui rerata pertumbuhan tanaman, keragaman sifat di antara famili yang diuji, taksiran nilai heritabilitas dan korelasi genetik antar sifat yang diamati.

\section{Analisis Data}

Data hasil pengukuran akan dianalisis untuk memperoleh informasi keragaman karakter di antara famili-famili yang diuji. Model ANOVA untuk uji keturunan half sib dengan rancangan RCBD ini, secara simbolik dapat ditulis sebagai berikut:

$\mathrm{Y}_{\mathrm{i} j \mathrm{k}}=\mu+\mathrm{B}_{\mathrm{i}}+\mathrm{Pj}+\mathrm{F}(\mathrm{P})_{\mathrm{kj}}+\mathrm{BF}(\mathrm{P})_{\mathrm{ik}}+\varepsilon_{\mathrm{ij} k}$

Keterangan:

$\mathrm{Y}_{\mathrm{ijk}}=$ pengamatan pada individu pohon ke-l dari sumber benih ke-j dari famili ke-k dalam blok ke-i; $\mu=$ rerata umum eksperimen; $\mathrm{B}_{\mathrm{i}}=$ pengaruh blok ke-i; $\mathrm{Pj}=$ pengaruh sumber benih ke-j; $\mathrm{F}(\mathrm{P}) \mathrm{kj}=$ pengaruh famili ke-k yang bersarang dalam sumber benih ke-j; $\mathrm{BF}(\mathrm{P})_{\mathrm{ik}}=$ pengaruh interaksi blok ke-i pada famili ke$\mathrm{k} ; \varepsilon_{\mathrm{ijk}}=$ error random.

Heritabilitas individu menurut Buijtenen dan Yeiser (1989) ditaksir mengikuti formula berikut ini :

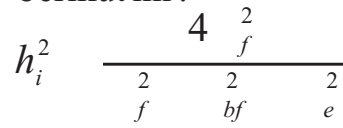

Keterangan :

$\mathrm{h}_{\mathrm{i}}{ }_{\mathrm{i}}=$ nilai heritabilitas individu; ${ }_{{ }_{f}}=$ komponen varians famili; $\quad{ }_{b f}=$ komponen varians interaksi blok dan famili; ${ }_{e}^{2}=$ komponen varians error; $b=$ rerata harmonikjumlah blok.
Korelasi fenotip antar sifat dihitung berdasarkan data masing-masing individu dengan menggunakan persamaan menurut Fins etal. (1992) yaitu:

$r_{12} \frac{\operatorname{Cov}_{12}}{1 \cdot 2}$

Keterangan:

r12 = korelasi antar sifat; Cov12 = kovarians antara dua sifat; $1=$ deviasi standar untuk sifat $1 ; 2=$ deviasi standar untuk sifat 2 .

Adapun korelasi genetik dengan persamaan berikut:

$r_{12} \frac{\operatorname{Cov}_{12}}{\sqrt{\begin{array}{c}2 \\ a 1\end{array}{ }^{2}}}$

Keterangan:

${ }_{\mathrm{r} / 2}=$ korelasi genetik; $\operatorname{Cov}_{12}=$ komponen kovarians antara dua sifat; ${ }_{\text {al }}=$ komponen varians aditif untuk sifat $1 ;{ }_{\mathrm{a} 2}^{2}=$ komponen varians aditif untuk sifat 2 .

\section{HASIL DAN PEMBAHASAN}

\section{A. Persen Hidup, Diameter dan Tinggi Tanaman}

Dari hasil analisis data uji keturunan sengon umur 4 bulan sebagaimana ditunjukkan Grafik 1 dan Tabel 2 di bawah, dapat diketahui bahwa persen hidup famili-famili sengon yang berasal 5 sumber benih itu berkisar antara $82,47 \%$ hingga $93,38 \%$ dengan persen hidup rata-rata secara keseluruhan mencapai $86,83 \%$. Pada data ini famili sengon asal dari Kediri tampak memiliki persen hidup paling tinggi sedangkan sebaliknya dialami famili sengon dari Candiroto. Namun, oleh karena umur tanaman ini masih muda dan masih memungkinkan dilakukan penyiangan, maka angka-angka persen hidup ini masih dapat berubah di masa datang.

Dari grafik pada Gambar 2 di atas terlihat bahwa rerata diameter terbesar mencapai $0,93 \mathrm{~cm}$ (Biak dan Kediri), dengan rerata terkecil $0,30 \mathrm{~cm}$ (Biak dan Candiroto). Rerata tinggi tanaman sengon tertinggi mencapai 1,98 m (Biak) dan terendah (Wamena dan Lombok). Susanto (1997) melaporkan bahwa rerata tinggi tanaman sengon terbaik pada umur 4 bulan mencapai $0,71 \mathrm{~m}$ (Jawa Timur) dan terkecil 0,37 cm (Manokwari). 


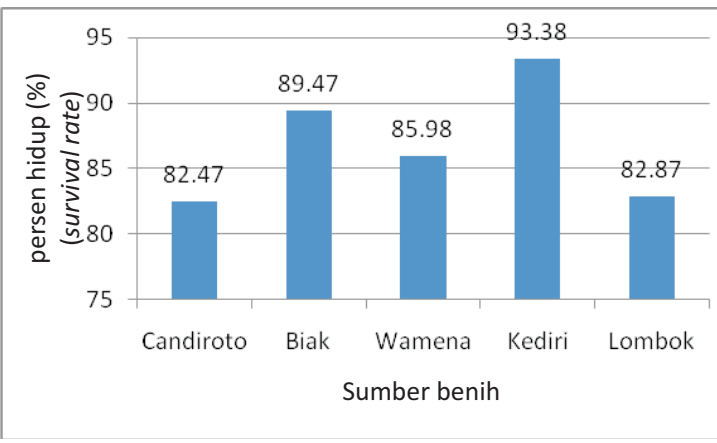

Gambar(Figure) 1. Persen hidup tanaman pada Kebun Benih Semai Uji Keturunan Sengon umur 4 bulan di Cikampek Jawa Barat (Growth survival of Sengon seedling seed orchard at 4 months old at Cikampek, West Java)

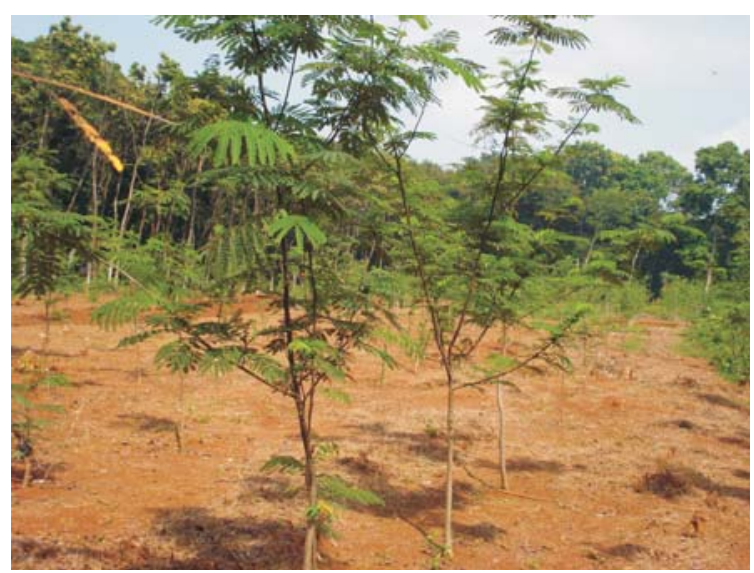

Gambar(Figure) 3. Salah satu variasi pertumbuhan yang ditunjukkan salah satu famili sengon pada KBSUK Sengon di Cikampek (One of growth's variation shown by a family of sengon in sengon's SSO in Cikampek, West Jawa)
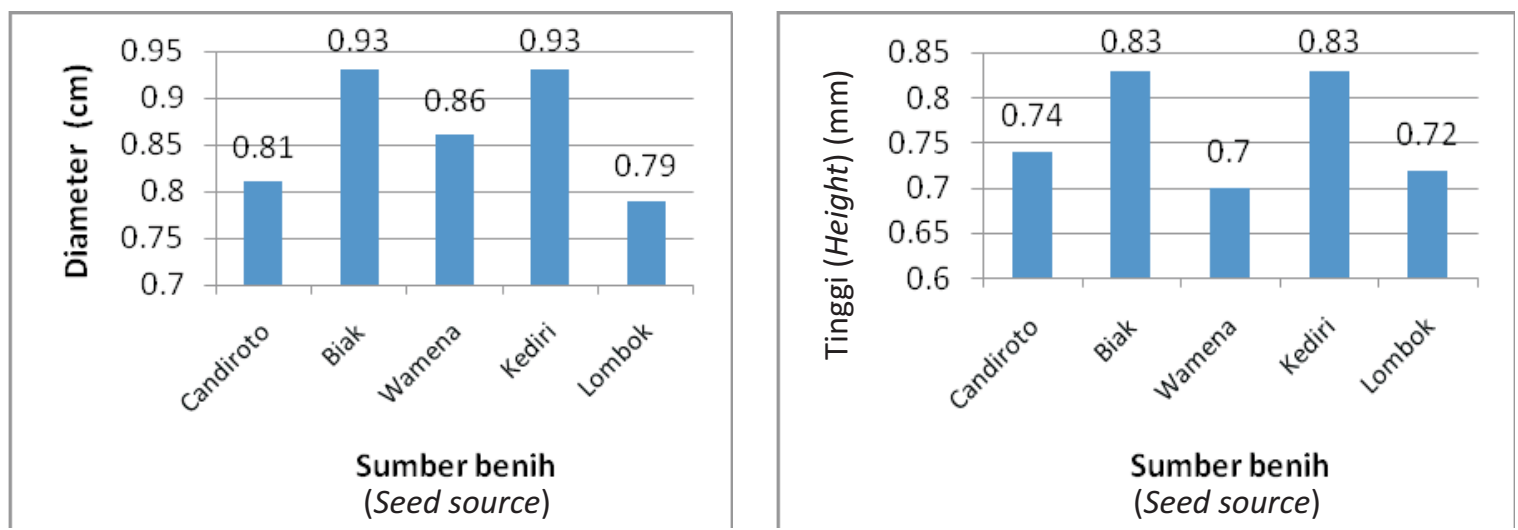

Gambar(Figure) 2. Grafik rerata diameter dan tinggi tanaman pada Kebun Benih Semai Uji Keturunan Sengon umur 4 bulan di Cikampek Jawa Barat (The average of stem diameter and height on Sengon seedling seed orchard at 4 months old at Cikampek West Java)

\section{B. Keragaman Sifat Pertumbuhan}

Dari hasil analisis varian terhadap sifat diameter batang dan tinggi tanaman, sebagaimana ditunjukkan Tabel 3 di bawah, tampak bahwa keragaman pertumbuhan sifatsifat itu sangat berbeda nyata diantara familifamili sengon yang diuji. Dari analisis yang mengidentifikasi sumber varian berupa asal sebaran pohon induk dan sifat famili-famili sengon itu sendiri terbukti bahwa sumber benih/provenans dan keragaman pada individu famili menjadi salah satu faktor penting timbulnya variasi sifat pertumbuhan.
Dari 5 sumber benih yang diuji memiliki posisi geografis yang berjauhan (Candiroto-Jawa Tengah, Biak Papua, Wamena Papua, Kediri Jawa Timur dan Lombok Nusa Tenggara Barat). menurut Zobel dan Talbert (1984) bahwa faktor geografis yang berjauhan ini sangat mempengaruhi sifat genetik tanaman. Demikian juga dalam penelitian lain di kebun benih semai uji keturunan sengon di Candiroto, Temanggung pada umur 4 bulan dilaporkan Susanto (1997) terbukti bahwa ada keragaman tinggi tanaman yang sangat signifikan diantara 9 provenansi (sumber benih) yang diuji. 
Tabel(Table) 3. Hasil analisis varian diameter dan tinggi tanaman KBSUK Sengon umur 4 bulan di Cikampek Jawa Barat (Varian analysis for stem diameter and height of Sengon Seedling Seed Orchard at 4 months old in Cikampek West Java)

\begin{tabular}{|c|c|c|c|c|}
\hline $\begin{array}{c}\text { Sumber variasi } \\
\text { (Variation source) }\end{array}$ & \begin{tabular}{|c|} 
Derajat \\
Bebas \\
$($ Degree of \\
freedom $)$ \\
\end{tabular} & $\begin{array}{l}\text { Kuadrat } \\
\text { rerata } \\
\text { Mean } \\
\text { quadrat }\end{array}$ & $\operatorname{Pr}>\mathrm{P}$ & $\begin{array}{l}\text { Kuadrat rerata harapan } \\
\text { Expected mean quadrat }\end{array}$ \\
\hline \multicolumn{5}{|l|}{$\frac{\text { A.Sifat Diameter }}{(\text { Diameter character })}$} \\
\hline Blok & 5 & 1,01 & 0.0001 & ${ }^{2}{ }_{\mathrm{e}}+2,58{ }_{\mathrm{bf}(\mathrm{P})}+199,23{ }_{\mathrm{b}}^{2}$ \\
\hline Provenans & 4 & 0,76 & 0.0001 & ${ }^{2}+2,52 \quad 2_{b f(P)}+14,54 \quad 2_{f(P)}+230,5 \quad{ }_{s b}$ \\
\hline Famili (P) & 75 & 0,21 & 0.0001 & ${ }^{2}+2,71{ }^{2}{ }_{b f(P)}+15,79{ }^{2}{ }_{f(P)}$ \\
\hline Blok x Fam. (P.) & 381 & 0,17 & 0.0001 & ${ }_{\mathrm{e}}^{2}+2,99{ }_{\mathrm{bf}(\mathrm{P})}$ \\
\hline Eror & 949 & 0,10 & & ${ }_{e}^{2}$ \\
\hline \multicolumn{5}{|l|}{$\begin{array}{l}\text { B. Sifat Tinggi } \\
\text { (Height character })\end{array}$} \\
\hline Blok & 5 & 0,44 & 0.0001 & ${ }_{\mathrm{e}}+2,58{ }_{\mathrm{bf}(\mathrm{P})}+199,23{ }_{\mathrm{b}}$ \\
\hline Sumber Benih & 4 & 0,72 & 0.0001 & ${ }^{2}{ }_{\mathrm{e}}+2,52 \quad{ }_{\mathrm{bf}(\mathrm{P})}+14,54 \quad{ }_{\mathrm{f}(\mathrm{P})}+230,5 \quad{ }_{\mathrm{sb}}$ \\
\hline Famili $(\mathrm{P})$ & 75 & 0,13 & 0.0001 & ${ }_{\mathrm{e}}+2,71{ }_{\mathrm{bf}(\mathrm{P})}+15,79{ }_{\mathrm{f}(\mathrm{P})}$ \\
\hline Blok x Fam. (P.) & 381 & 0,09 & 0.0001 & ${ }_{\mathrm{e}}^{2}+2,99{ }^{2}{ }_{\mathrm{bf}}(\mathrm{P})$ \\
\hline Eror & 949 & 0,06 & & ${ }_{\mathrm{e}}^{2}$ \\
\hline
\end{tabular}

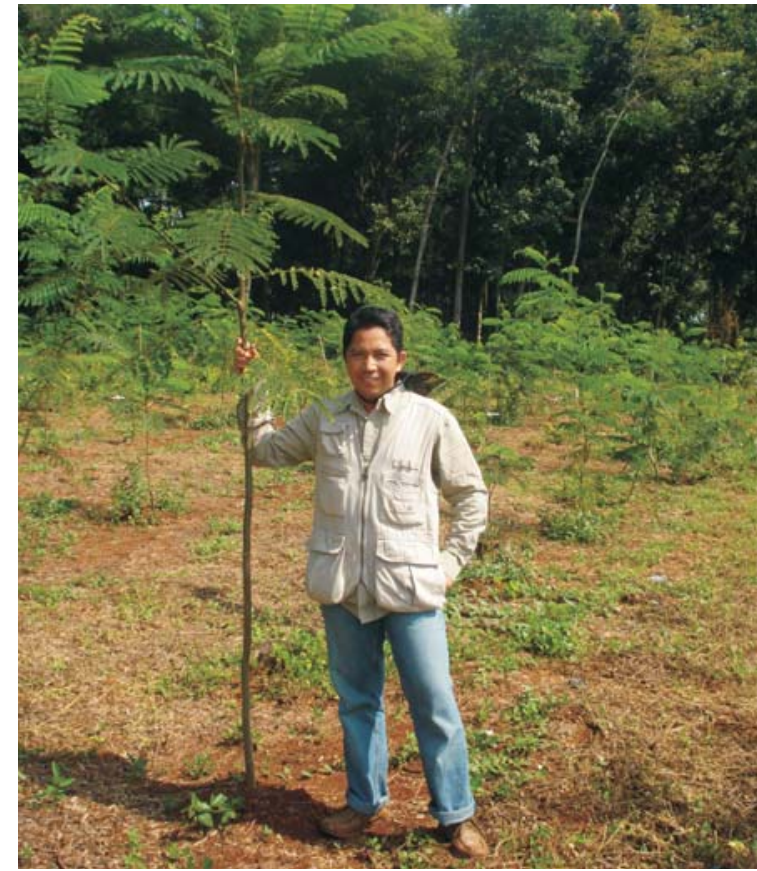

Gambar(Figure) 4. Salah satu tanaman terbaik pada KBSUK Sengon umur 4 bulan di Cikampek (One of the best plant on Sengon SSO at 4 months old in Cikampek, West Java)
Mengetahui sejak awal adanya keragaman sifat diameter dan tinggi tanaman sangat penting maknanya bagi plot pemuliaan tanaman hutan yang memiliki tujuan akhir menghasilkan individu tanaman sengon unggul untuk tujuan kayu pertukangan, meskipun beberapa sifat lain seperti tinggi bebas cabang, bentuk batang, sifat kayu dan tahan serangan hama penyakit kemungkinan besar akan menjadi variabel signifikan untuk diintegrasikan dalam proses seleksi pada plot kebun benih sengon ini dimasa datang. Oleh karena itu maka evaluasi periodik pertumbuhan tanaman sengon ini akan terus dilakukan hingga mencapai tujuan yang diinginkan.

\section{Nilai Heritabilitas dan Korelasi Antar Sifat}

Untuk mengetahui proporsi faktor genetik yang diturunkan dari induk kepada keturunannya maka dilakukan penaksiran nilai heritabilitas. Dari hasil perhitungan diketahui bahwa taksiran nilai heritabilitas individu sifat diameter tanaman sengon umur 4 bulan ini $(0,1)$ lebih rendah daripada sifat tinggi tanaman $(0,16)$. 
Mengacu pada klasifikasi yang dibuat Cotteril dan Dean (1990), bahwa nilai heritabilitas individu $\left(\mathrm{h}_{\mathrm{i}}{ }^{2}\right) \quad 0,1$ berarti rendah; $0,1 \quad$ - 0,3 berarti sedang/ moderat; 0,3 berarti tinggi, sehingga klasifikasi taksiran nilai heritabilitas diameter dan tinggi tanaman sengon ini tergolong sedang/moderat. Hal ini juga berarti bahwa variasi pertumbuhan sifat diameter dan tinggi tanaman ini dipengaruhi pula oleh faktor genetik selain oleh faktor lingkungan.

Pengaruh faktor genetik pada tanaman sengon pada umur tanaman muda ini tampaknya belum terksepresi dengan baik. Fakta ini berbeda dengan yang digambarkan Susanto (1999) bahwa nilai heritabilitas famili sifat diameter pada KBSUK Sengon umur 3 tahun di Candiroto mencapai 0,68 dan tinggi pohon mencapai 0,78, dan yang konsisten dari fakta ini adalah perolehan heritabilitas tinggi tanaman sengon tetap lebih besar daripada heritabilitas diamater batang.

Untuk melihat keeratan hubungan baik fenotif maupun genetik diantara dua sifat pertumbuhan tanaman sengon pada KBSUK di Cikampek ini maka dilakukan perhitungan korelasi antar sifat. Hasil analisa data menunjukkan bahwa korelasi fenotip diameter $x$ tinggi tanaman yang diperoleh adalah 0,78 dan korelasi genetik mencapai 0,90. Perbedaan yang cukup jauh kedua korelasi ini mengindikasikan bahwa keeratan fenotif dari kedua sifat itu, tidak selalu dapat mencerminkan tingkat keeratan hubungan genetik di dalamnya oleh karena adanya varian lingkungan yang cukup besar. Terbukti juga dari taksiran nilai heritabilitas kedua sifat umur 4 bulan ini yang rendah dan moderat yang mengindikasikan kuatnya pengaruh lingkungan itu.

\section{KESIMPULAN}

Dari evaluasi KBSUK Sengon umur 4 bulan di Cikampek ini maka dapat ditarik kesimpulan sebagai berikut:

1. Persen hidup rata-rata famili-famili sengon secara umum baik.

2. Variasi pertumbuhan diameter batang dan tingi tanaman dipengaruhi oleh faktor keragaman sumber benih/provenans dan famili yang diuji.

3. Famili-famili dari Biak-Papua dan Kediri-
Jawa Timur mengindikasikan pertumbuhan diameter dan tinggi terbaik pada umur 4 bulan.

4. Nilai heritabilitas sifat diameter batang dan tinggi tanaman termasuk sedang, hal ini memberi indikasi bahwa keragaman pertumbuhan diameter dan tinggi itu dipengaruhi oleh faktor genetik selain oleh faktor lingkungan.

5. Korelasi sifat tinggi dan diameter cukup kuat, sehingga perbaikan satu sifat itu akan secara langsung memperbaiki sifat lainnya.

\section{UCAPAN TERIMA KASIH}

Kami mengucapkan terima kasih yang tidak terhingga kepada Dr. Anto Rimbawanto sebagai koordinator penelitian Sengon, Bp. Burhan Ismail $\mathrm{BScF}, \mathrm{SP}$ sebagai penanggungjawab pembangunan plot ini, petugas KHDTK Cikampek : Bpk. Ucup, Sdr. Yusup Obama dan Sdr. Deni Skotlet dan teknisi khusus Diro E.P. SHut.T serta pihak-pihak lain yang tidak dapat disebutkan satu per satu.

\section{DAFTAR PUSTAKA}

Achmad, B., S. Mulyana dan A. Badrunasar. 2004. Pemeliharaan Hutan Rakyat Jenis Sengon. Albasia Vol.1 No.2 Maret 2004. Loka Penelitian dan Pengembangan Hutan Monsoon, Ciamis.

Alrasyid, H. 1997. Evaluasi penerapan TJTI. Makalah Seminar hasil-hasil penelitian. Pusat Litbang Hutan dan Konservasi Alam. Bogor.

Andayani, W. 2003. Efisiensi pemasaran kayu sengon rakyat di Daerah Sentra Produksi Kabupaten Wonosobo. Jurnal Hutan Rakyat, Vol. V, No. 1, 2003. Fakultas Kehutanan, UGM, Yogyakarta

Buitjtenen, J.P.V. and J.L. Yeiser. Exercise in Quantitative Genetic of Forest Trees. Forest Genetic Laboratory. Texas A\&M University.

Cotteril, P.P and C.A. Dean. 1990. Successful Tree Breeding with Index Selection. CSIRO Devision of Forestry and forest Product. Australia 
Fins, L., Sharon T.F., dan Janeth V.B. 1992. Handbook of Quantitatif Forest Genetics. Kluwer Academic Publisher. Dodrecht, The Netherland.

Siregar, I.Z, T. Yunanto dan J. Ratnasari. 2008. Prospek Bisnis, Budidaya, Panen dan Pasca Panen Kayu Sengon. Penebar swadaya. Jakarta

Susanto, M. 1999. Evaluasi awal kebun benih uji keturunan jenis Paraserianthes falcataria umur 4 bulan di Candiroto Jawa Tengah. Buletin Penelitian Pemuliaan Pohon. Vol. 3 No. 1. Badan Litbang Departemen
Kehutanan dan Perkebunan. BP3BTH. Yogyakarta.

Susanto, M. 1999. Evaluasi awal kebun benih uji keturunan jenis Paraserianthes falcataria umur 3 tahun di Candiroto Jawa Tengah. Buletin Penelitian Pemuliaan Pohon Vol. 3. No. 1. Badan Litbang Departemen Kehutanan dan Perkebunan. BP3BTH. Yogyakarta.

Syahri dan T. Nurhayati. 1991. Analisis kimia kayu dan kulit kayu jeungjing. Pusat Litbang Hasil Hutan. Laporan Hasil Penelitian (Tidak diterbitkan). 